\title{
Role of clinical questionnaires in optimizing everyday care of chronic obstructive pulmonary disease
}

Paul W Jones'

David Price ${ }^{2}$

Thys van der Molen ${ }^{3}$

'Cardiac and Vascular Medicine, St George's, University of London, UK; ${ }^{2}$ Centre of Academic Primary Care, University of Aberdeen, UK; ${ }^{3}$ Department of General Practice, University Medical Center Groningen, The Netherlands

Correspondence: Paul W Jones Cardiac and Vascular Medicine, St George's, University of London, Cranmer Terrace, SWI7 ORE, UK

Tel +44020 87255372

Fax +440208725 5955

Email pjones@sgul.ac.uk
This article was published in the following Dove Press journal:

International Journal of COPD

25 May 20II

Number of times this article has been viewed

Abstract: Chronic obstructive pulmonary disease (COPD) is a leading cause of disability in all its stages, and death in patients with moderate or severe obstruction. At present, COPD is suboptimally managed; current health is often not measured properly and hardly taken into account in management plans, and the future risk for patients with regard to health status and quality of life is not being evaluated. This review addresses the effect of COPD on the lives of patients and examines ways in which existing assessment tools meet physicians' needs for a standardized, simple method to measure consistently the full impact of COPD on patients in routine clinical practice. Current assessment of COPD severity tends to focus on airflow limitation, but this does not capture the full impact of the disease and is not well correlated with patient perception of symptoms and health-related quality of life. Qualitative studies have demonstrated that patients usually consider COPD impact in terms of frequency and severity of symptoms, and physical and emotional wellbeing. However, patients often have difficulty expressing their disease burden and physicians generally have insufficient time to collect this information. Therefore, it is important that methods are implemented to help generate a more complete understanding of the impact of COPD. This can be achieved most efficiently using a quick, reliable, and standardized measure of disease impact, such as a short questionnaire that can be applied in daily clinical practice. Questionnaires are precision instruments that contribute sensitive and specific information, and can potentially help physicians provide optimal care for patients with COPD. Two short, easy-to-use, specific measures, ie, the COPD Assessment Test and the Clinical COPD Questionnaire, enable physicians to assess patients' health status accurately and improve disease management. Such questionnaires provide important measurements that can assist primary care physicians to capture the impact of COPD on patients' daily lives and wellbeing, and improve long-term COPD management.

Keywords: chronic obstructive pulmonary disease, COPD assessment test, disease management, health status, quality of life, questionnaire

\section{Background}

Chronic obstructive pulmonary disease (COPD) is a major public health problem of high and increasing prevalence, ${ }^{1-5}$ and is a leading cause of disability in all its stages ${ }^{6,7}$ and death in patients with moderate or severe obstruction. ${ }^{8-10}$ COPD imposes a profound burden on patients, including medical emergencies, hospitalizations, work absenteeism, and activity limitations. Ultimately, this has a significant physical and emotional impact on patients. ${ }^{11}$

COPD, as defined by airflow limitation, is often underdiagnosed ${ }^{12-14}$ and undertreated, ${ }^{15}$ leading to poor quality of life for patients. ${ }^{16}$ Current assessments of 
COPD severity focus on the amount of air that patients can forcibly exhale from their lungs in the first second of a forced exhalation $\left(\mathrm{FEV}_{1}\right)$, but this alone does not capture the full impact of the disease. ${ }^{17}$ As a consequence, patients with COPD are often suboptimally managed. ${ }^{18,19}$ The future risk for patients with COPD with regard to health status and quality of life is not currently being evaluated routinely, but it is likely that this will provide a marker of both current impact and future risk in these patients. ${ }^{20-24}$

Improved COPD management requires a range of patient assessments, including lung function, exacerbation episodes, exercise tolerance, and impact on health status. However, patients often have difficulty expressing the burden of their disease and physicians generally do not have sufficient time to collect this information. Therefore, it is important that methods are implemented to enable clinicians to reach a more complete understanding of the impact of the disease on their patients and identify specific needs. The most efficient way to achieve this is to use a quick, reliable, and standardized measure of disease impact, such as a short questionnaire, that can be applied in daily clinical practice to provide physicians with additional useful information. Validated patient-reported outcomes, eg, measurements of health status (health-related quality of life [HRQoL]), or functional status are now recognized as being key in capturing the patient's experience of important aspects of health in chronic disease. ${ }^{25}$ Use of these measures will enable physicians to determine what is really important to the individual patient and highlight differences between patients.

In conjunction with patient-reported measures, health care systems need to be more organized and focused towards meeting the current and future needs of patients with COPD. Patients with chronic disease require both regular clinician assessments and self-management. Application of the chronic care model, which includes fundamental elements (eg, the community, health care system, and patient self-management) needed to support high-quality care for patients with chronic disease, could potentially improve COPD management. ${ }^{26-28}$

The management of COPD is now directed towards symptomatic benefit, in terms of improved HRQoL and exercise tolerance, and risk reduction (eg, exacerbations, hospital admissions, and death). Assessment of COPD risk can now be done in routine clinical practice using simple multidimensional prognostic scaling systems, such as the DOSE index. ${ }^{29}$ The aim of this review, however, is to address the impact of COPD on patients' lives and to discuss ways in which the new assessment tools can meet physicians' needs for a standardized, simple method to measure consistently the full impact of COPD on patients in routine clinical practice.

\section{Measuring impact of COPD on patients}

The burden of COPD on patients and their families is high. ${ }^{13,30-32}$ Furthermore, it is not limited to patients with severe COPD, but is also very prominent in younger patients with only mild or moderate airway obstruction, limiting them in their daily lives. ${ }^{33}$ In general, patients have a restricted understanding of both the extent of their loss of pulmonary function and the severity of their COPD. In the Confronting COPD International Survey, patients' perceptions of the severity of their COPD did not consistently correspond with the degree of severity indicated by the Medical Research Council (MRC) dyspnea (breathlessness) scale. ${ }^{16}$ In addition, most patients do not appear to place the same level of importance on their exacerbation episodes as health care providers, ${ }^{34}$ and a recent study showed that patients generally report smaller changes in HRQoL outcome measures as more clinically meaningful than do physicians. ${ }^{35}$ Thus, the provision of measures to document clinical outcomes can help both patients and health care providers improve their knowledge about the impact of COPD on patient health.

Surveys have indicated that patients usually consider the impact of COPD in terms of symptom frequency and severity, and physical and emotional wellbeing. ${ }^{16}$ In the Confronting COPD in America survey, 90\% of individuals with COPD experienced symptoms either every day or most days during their worst three-month period in the past year (Figure 1). ${ }^{36}$

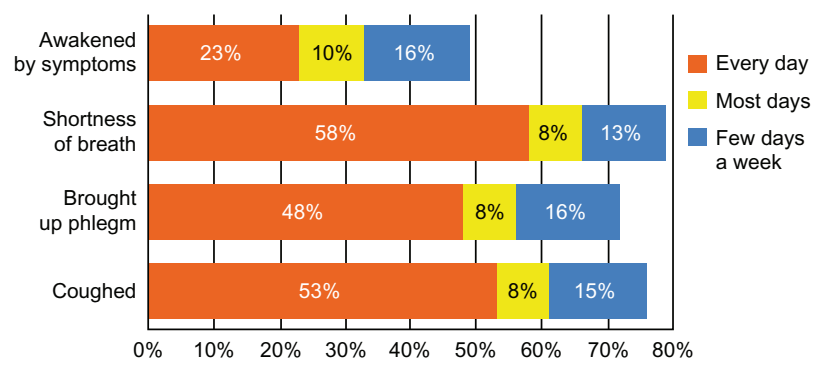

Figure I Symptom frequency in individuals with COPD (evaluation of worst threemonth period in past year). Patients participating in the Confronting COPD in America survey were asked about the frequency of their symptoms during their worst three-month period in the past year (ie, "Has there been any three-month period in the past year when you experienced ... [read item] - every day, most days a week, a few days a week, a few days a month, less than that?"). A high proportion of patients reported that they frequently experienced specific disease-associated outcomes during their worst period in the past year. ${ }^{36}$

Reproduced with permission from GlaxoSmithKline. 
Also, patients use language such as "good" and "bad" days to define how COPD influences their HRQoL, so patients' self-reported assessments are important when evaluating the intensity of symptoms, such as dyspnea and fatigue, and their impact on HRQoL. ${ }^{37}$

\section{Changing health status}

A study in patients with stable COPD showed that changes in health status assessed by patient-reported measures (eg, the St George's Respiratory Questionnaire [SGRQ], Chronic Respiratory Questionnaire [CRQ], MRC dyspnea scale, and the Hospital Anxiety and Depression Scale [HADS]) worsened significantly over time. ${ }^{38}$ However, deteriorations in patient-reported outcomes (eg, symptoms, limitation of daily activities, and wellbeing) showed only a weak correlation with changes in physiological indices such as $\mathrm{FEV}_{1}$ and maximal oxygen uptake measured at peak exercise. ${ }^{38}$ Those authors concluded that to capture the overall deterioration in patients' health status due to COPD, patient-reported outcomes should be followed independently of physical outcomes. ${ }^{38}$

\section{Challenges in providing chronic care for patients with COPD}

During a consultation, patients tend to understate their disease severity, under-report COPD exacerbations, and do not convey the impact of the disease on their quality of life. In addition, patients often only present to their physicians when their condition has progressed significantly leading to a reduced HRQoL. ${ }^{14,39}$ Consequently, there is a need to assess patients' health status to enable optimal disease management.

\section{Clinical assessment questionnaires in COPD}

Physicians need to consider several factors when assessing patients with COPD. The impact of COPD depends not only on the degree of airflow limitation but also on the severity of symptoms, systemic effects, and any comorbidities present. ${ }^{2,31}$ When a patient experiences an exacerbation they often require several weeks of recovery, ${ }^{24}$ sustained worsening of symptoms can also have a significant impact on patients' HRQoL and mortality. ${ }^{40-44}$ Importantly, reductions in objective pulmonary function measurements, such as $\mathrm{FEV}_{1}$, are not well correlated with patients' perception of symptoms and HRQoL (Figure 2). ${ }^{17,45}$ When managing patients with COPD it is therefore necessary to measure both pulmonary function and HRQoL.

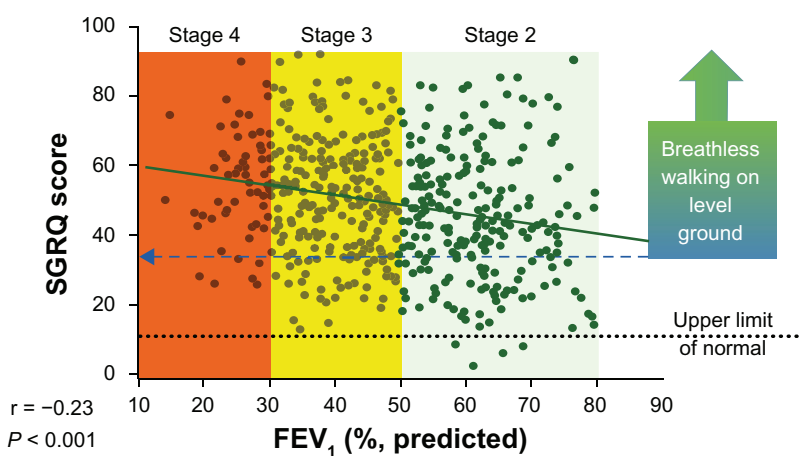

Figure 2 Relationship between health status as measured by the SGRQ, and FEV and GOLD stage. Patients' perception of symptoms and health-related quality of life, as assessed by the SGRQ, were not well correlated with objective pulmonary function measurements, such as FEV, and GOLD stage.

Adapted from Jones PW. Health status measurement in chronic obstructive pulmonary disease. Thorax. 200 I;56:880-887 with permission from the BMJ Publishing Group Limited. ${ }^{17}$

Abbreviations: SGRQ, St George's Respiratory Questionnaire; FEV , forced expiratory volume in one second; GOLD, Global Initiative for Chronic Obstructive Lung Disease.

Physicians require help in realizing the full impact of COPD on their patients. Qualitative studies showed that patients with COPD have difficulty placing themselves along a continuum of disease severity and relating their severity to that of other patients with COPD. During development of the COPD Assessment Test (CAT), patients indicated that they would like to have a method available that would allow them to both assess their own disease severity and communicate this information to their physicians. ${ }^{46}$

Standardized assessments, beyond peak airflow (maximally forced expiration initiated at full inspiration) currently used to assess patients in clinical practice evaluate multidimensional domains (symptoms, physical, psychological, and social) affected by COPD. Examples of disease-specific instruments include the MRC dyspnea scale, the Clinical COPD Questionnaire (CCQ), and the CAT. ${ }^{46-48}$ These measures can be assessed in terms of their relative reliability, validity, responsiveness, acceptability, and feasibility in everyday clinical practice. ${ }^{25}$ Other questionnaires such as the SGRQ, CRQ, and Short Form 36-item Health Survey (SF-36) comprise many more questions and consequently are not suitable for use in daily clinical practice, so these questionnaires are not discussed further. A comprehensive review of available questionnaires is currently being undertaken by the International Primary Care Respiratory Group (www.theipcrg.org/).

Questionnaires are precision instruments that can provide sensitive and specific information and, if sufficiently short and simple, can enable physicians in routine clinical practice to assess the health status of their patients accurately, thereby allowing improved COPD management. 


\section{CLINICAL COPD QUESTIONNAIRE}
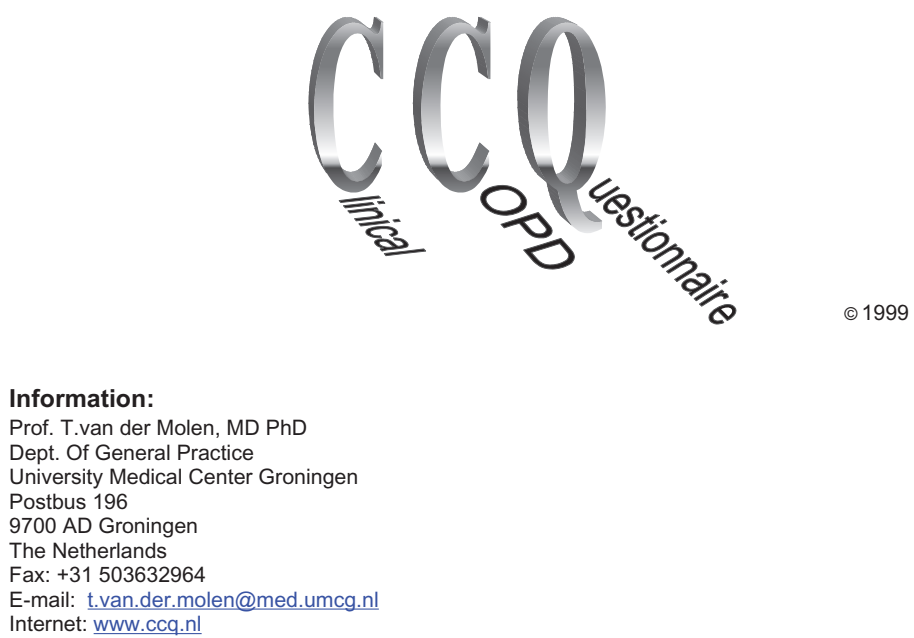

Patient number:

Date:

\section{CLINICAL COPD QUESTIONNAIRE}

Please circle the number of the response that best describes how you have been feeling during the past week. (Only one response for each question).

On average, during the past week, how often did you feel:

I. Short of breath at rest?

2. Short of breath doing physical activities?

3. Concerned about getting a cold or your breathing getting worse?

4. Depressed (down) because

of your breathing problems?

In general, during the past week,

how much of the time:

5. Did you cough?

6. Did you produce phlegm?

On average, during the past week, how limited were you in these activities because of your breathing problems:

7. Strenuous physical activities (such as climbing stairs, hurrying, doing sports)?

8. Moderate physical activities (such as walking, housework, carrying things)?

9. Daily activities at home (such as dressing, washing yourself)?

10. Social activities (such as talking, being with children, visiting friends/relatives)?

(C) The CCQ is copyrighted. It may not be altered, sold (paper or electronic), translated or adapted for another medium without the permission of

T. van der Molen, Dept. of General Practise, University Medical Center Groningen, Postbus 196, 9700 AD Groningen, The Netherlands.

Figure 3 The clinical COPD questionnaire.

Reproduced with permission from Thys van der Molen.

\begin{tabular}{|c|c|c|c|c|c|c|}
\hline never & $\begin{array}{c}\text { hardly } \\
\text { ever }\end{array}$ & $\begin{array}{l}\text { a few } \\
\text { times }\end{array}$ & $\begin{array}{l}\text { several } \\
\text { times }\end{array}$ & $\begin{array}{l}\text { many } \\
\text { times }\end{array}$ & $\begin{array}{c}\text { a great } \\
\text { many times }\end{array}$ & $\begin{array}{l}\text { almost } \\
\text { all the time }\end{array}$ \\
\hline 0 & I & 2 & 3 & 4 & 5 & 6 \\
\hline 0 & I & 2 & 3 & 4 & 5 & 6 \\
\hline 0 & 1 & 2 & 3 & 4 & 5 & 6 \\
\hline 0 & I & 2 & 3 & 4 & 5 & 6 \\
\hline 0 & I & 2 & 3 & 4 & 5 & 6 \\
\hline 0 & I & 2 & 3 & 4 & 5 & 6 \\
\hline not limited & very slightly & slightly & moderately & very & extremely & totally limited/ \\
\hline at all & limited & limited & limited & limited & limited & or unable to do \\
\hline 0 & I & 2 & 3 & 4 & 5 & 6 \\
\hline 0 & I & 2 & 3 & 4 & 5 & 6 \\
\hline 0 & I & 2 & 3 & 4 & 5 & 6 \\
\hline 0 & I & 2 & 3 & 4 & 5 & 6 \\
\hline
\end{tabular}


Your name:

Today's date:

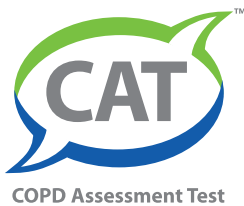

\section{How is your COPD? Take the COPD Assessment Test ${ }^{\mathrm{TM}}$ (CAT)}

This questionnaire will help you and your healthcare professional measure the impact COPD (Chronic Obstructive Pulmonary Disease) is having on your wellbeing and daily life. Your answers, and test score, can be used by you and your healthcare professional to help improve the management of your COPD and get the greatest benefit from treatment.

For each item below, place a mark $(X)$ in the box that best describes you currently. Be sure to only select one response for each question.

Example: I am very happy 0 (3) 1 am very sad

I never cough

\section{(0) (1) (2) I cough all the time}

I have no phlegm (mucus)

in my chest at all

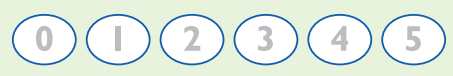

My chest is completely

full of phlegm (mucus)

\section{My chest does not \\ feel tight at all

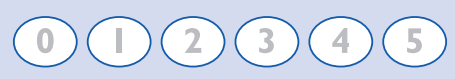 \\ My chest feels \\ very tight}

\section{When I walk up a hill or one flight of stairs I am

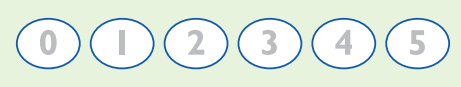
not breathless

When I walk up a hill or one flight of stairs I am very breathless

I am very limited doing

I am not limited doing any activities at home

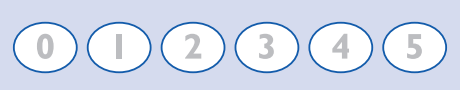
activities at home

\begin{tabular}{|l|l|l|l|l|}
\hline $\begin{array}{l}\text { I am confident leaving } \\
\text { my home despite } \mathrm{my} \\
\text { Iung condition }\end{array}$ \\
\hline I sleep soundly
\end{tabular}

\section{I have lots of energy}

I have no energy at all 


\section{Medical research council dyspnea scale}

The MRC dyspnea scale, recommended by the Global Initiative for Chronic Obstructive Lung Disease (GOLD) ${ }^{2}$ and other national guidelines, was developed by Fletcher et al while studying the respiratory problems of Welsh coalminers in the $1940 \mathrm{~s} .{ }^{48,49} \mathrm{It}$ is short (comprises five dyspnea items) and has been in use for many years for grading the effect of breathlessness on daily activities. It is simple to administer because it allows patients to indicate the extent to which their breathlessness affects their mobility. However, it only measures one aspect of the patient experience (ie, perceived respiratory disability) and is poorly responsive to change.

\section{Clinical COPD questionnaire}

The CCQ (Figure 3) consists of three domains and 10 items, ie, symptoms (four items), functional state (four items), and mental state (two items). All scores range from $0-6\left(0\right.$, no impairment). ${ }^{47}$ The CCQ was developed in consultation with 32 patients in two countries, and item reduction performed in collaboration with 79 clinicians worldwide. Patients can complete the CCQ quickly (in approximately two minutes) and it is straightforward to score; this allows data to be instantly collected and processed, enabling its use in everyday practice, clinical trials, and qualityof-care monitoring. Three studies in the Netherlands, Italy, and Sweden provided strong supporting evidence for the reliability, validity, and responsiveness of the CCQ. ${ }^{47,50,51} \mathrm{~A}$ change in the total CCQ score of $\geq 0.4$ from one patient visit to the next is considered to be significant (ie, the minimum clinically important difference). ${ }^{52}$ The CCQ is freely available (in 53 languages) for use in clinical practice (www.ccq.nl).

\section{COPD assessment test}

The CAT (Figure 4) is a short (eight-item) and simpleto-administer patient-completed questionnaire designed for routine use in clinical practice. It covers a wide range of effects of COPD, including cough and sputum, chest symptoms, activity limitation, sleep, fatigue, and confidence leaving home. Patients can complete the CAT quickly (in approximately two minutes) by themselves in the doctor's waiting room. Development of the CAT involved consultation with a large number of patients at each stage of the process. Items covered in the CAT can help physicians measure the overall impact that COPD is having on patient wellbeing and daily life. Thus, the CAT provides a holistic measure of COPD health status; ${ }^{46}$ it should facilitate a factbased, physician-patient dialog and improve communication to present a common understanding and grading of the impact of COPD. It is supported by strong evidence for reliability and by preliminary data for construct and discriminant validity ${ }^{46}$ additional validity analyses are ongoing. The minimum clinically important difference in CAT score is yet to be established formally, ${ }^{53}$ but based upon mapping from the SGRQ at a population level it will be approximately 1.6 units. At the individual patient level, a change in CAT score of $\geq 2$ units will be clinically significant. The CAT is freely available (although GlaxoSmithKline owns the copyright to protect it from unauthorized changes) for use in daily clinical practice (www.catestonline.org).

\section{Summary}

An increased understanding of the full impact of COPD on patients and their carers should enable physicians to provide targeted intervention and improve patients' HRQoL.

Care for patients with COPD can be optimized best by use of reliable, standardized measurements of overall disease impact. The measures should be appropriate to the question being addressed, sensitive to changes that are relevant to patients, capable of providing physicians with meaningful scores, and acceptable to both patients and health care providers. ${ }^{54}$ The questionnaires reviewed here have those attributes and are quick and easy to use during consultations. Incorporation of questionnaires such as these into the consultation process will enable improved patient-physician partnership decision-making, help prioritize patients for primary care review, and drive effective management of patients with COPD.

\section{Acknowledgment}

Editorial support in the form of development of the manuscript first draft, collating author comments, and referencing was provided by Dr Richard Barry (Quintiles Medical Communications) and was funded by GlaxoSmithKline.

\section{Disclosure}

PWJ has received consultancy and advisory board fees from GlaxoSmithKline, AstraZeneca, Almirall, Boehringer Ingelheim, Roche, and Spiration; he has also received lecture fees from GlaxoSmithKline. DP has consultant arrangements with Boehringer Ingelheim, GlaxoSmithKline, Merck, Novartis, and Teva. $\mathrm{He}$ and/or his research team have received grants and support for research in respiratory disease from the following organizations in the past five years: UK National Health Service, Aerocrine, AstraZeneca, Boehringer Ingelheim, GlaxoSmithKline, Merck, Novartis, Nycomed, Pfizer, and Teva. He has spoken 
for Boehringer Ingelheim, Chiesi, GlaxoSmithKline, Merck, Pfizer, and Teva. TVDM has participated as a speaker at several conferences financed by ALTANA, GlaxoSmithKline, and AstraZeneca. He has served on the advisory boards for Merck, AstraZeneca, and Nycomed. He has received research grants from ALTANA, AstraZeneca, and MSD.

\section{References}

1. Mathers CD, Stein C, Ma Fat D, et al. Global Burden of Disease 2000: Version 2 methods and results. Geneva, Switzerland: World Health Organization; 2002.

2. Global Initiative for Chronic Obstructive Lung Disease. Global strategy for the diagnosis, management, and prevention of chronic obstructive pulmonary disease (updated 2009). Global Initiative for Chronic Obstructive Lung Disease; 2009. Available from: http://goldcopd.com/. Accessed April 1, 2011.

3. Menezes AM, Perez-Padilla R, Hallal PC, et al. Worldwide burden of COPD in high- and low-income countries. Part II. Burden of chronic obstructive lung disease in Latin America: The PLATINO study. Int $J$ Tuberc Lung Dis. 2008;12:709-712.

4. De Oca MM, Talamo C, Halbert RJ, et al. Frequency of self-reported COPD exacerbation and airflow obstruction in five Latin American cities: The Proyecto Latinoamericano de Investigacion en Obstruccion Pulmonar (PLATINO) study. Chest. 2009;136:71-78.

5. Buist AS, Vollmer WM, McBurnie MA. Worldwide burden of COPD in high- and low-income countries. Part I. The burden of obstructive lung disease (BOLD) initiative. Int J Tuberc Lung Dis. 2008;12:703-708.

6. Braido F, Baiardini I, Menoni S, et al. Disability in COPD and its relationship to clinical and patient-reported outcomes. Curr Med Res Opin. March 8, 2011. [Epub ahead of print].

7. Jones PW, Brusselle G, Dal Negro RW, et al. Health-related quality of life in patients by COPD severity within primary care in Europe. Respir Med. 2011;105:57-66.

8. Decramer M, Celli B, Kesten S, et al. Effect of tiotropium on outcomes in patients with moderate chronic obstructive pulmonary disease (UPLIFT): A prespecified subgroup analysis of a randomised controlled trial. Lancet. 2009;374:1171-1178.

9. Hurst JR, Vestbo J, Anzueto A, et al. Susceptibility to exacerbation in chronic obstructive pulmonary disease. $N$ Engl J Med. 2010;363: $1128-1138$.

10. Jenkins CR, Jones PW, Calverley PM, et al. Efficacy of salmeterol/ fluticasone propionate by GOLD stage of chronic obstructive pulmonary disease: Analysis from the randomised, placebo-controlled TORCH study. Respir Res. 2009;10:59.

11. ZuWallack R. How are you doing? What are you doing? Differing perspectives in the assessment of individuals with COPD. COPD. 2007;4:293-297.

12. Buist AS, McBurnie MA, Vollmer WM, et al. International variation in the prevalence of COPD (the BOLD Study): A population-based prevalence study. Lancet. 2007;370:741-750.

13. Maleki-Yazdi MR, Lewczuk CK, Haddon JM, Choudry N, Ryan N. Early detection and impaired quality of life in COPD GOLD stage 0 : A pilot study. COPD. 2007;4:313-320.

14. Kornmann O, Beeh KM, Beier J, et al. Newly diagnosed chronic obstructive pulmonary disease. Clinical features and distribution of the novel stages of the Global Initiative for Obstructive Lung Disease. Respiration. 2003;70:67-75.

15. Janse AJ, Gemke RJ, Uiterwaal CS, et al. Quality of life: Patients and doctors don't always agree: A meta-analysis. J Clin Epidemiol. 2004; 57:653-661.

16. Rennard S, Decramer M, Calverley PM, et al. Impact of COPD in North America and Europe in 2000: Subjects' perspective of Confronting COPD International Survey. Eur Respir J. 2002;20:799-805.
17. Jones PW. Health status measurement in chronic obstructive pulmonary disease. Thorax. 2001;56:880-887.

18. Mannino DM, Homa DM, Akinbami LJ, Ford ES, Redd SC. Chronic obstructive pulmonary disease surveillance - United States, 1971-2000. MMWR Surveill Summ. 2002;51(6):1-16.

19. Hansen JG, Pedersen L, Overvad K, et al. The prevalence of chronic obstructive pulmonary disease among Danes aged 45-84 years: Population-based study. COPD. 2008;5:347-352.

20. Domingo-Salvany A, Lamarca R, Ferrer M, et al. Health-related quality of life and mortality in male patients with chronic obstructive pulmonary disease. Am J Respir Crit Care Med. 2002;166:680-685.

21. Gudmundsson G, Gislason T, Janson C, et al. Risk factors for rehospitalisation in COPD: Role of health status, anxiety and depression. Eur Respir J. 2005;26:414-419.

22. Jones P, Lareau S, Mahler DA. Measuring the effects of COPD on the patient. Respir Med. 2005;99 Suppl B:S11-S18.

23. Oga T, Nishimura K, Tsukino M, Sato S, Hajiro T. Analysis of the factors related to mortality in chronic obstructive pulmonary disease: Role of exercise capacity and health status. Am J Respir Crit Care Med. 2003;167:544-549.

24. Spencer S, Jones PW. Time course of recovery of health status following an infective exacerbation of chronic bronchitis. Thorax. 2003;58: 589-593.

25. Patient-reported Health Instruments Group. A structured review of patient-reported measures in relation to selected chronic conditions, perceptions of quality of care and carer impact. Oxford, UK: National Centre for Health Outcomes Development, Department of Health, University of Oxford; 2006.

26. Wagner EH. Chronic disease management: What will it take to improve care for chronic illness? Eff Clin Pract. 1998;1:2-4.

27. Adams SG, Smith PK, Allan PF, et al. Systematic review of the chronic care model in chronic obstructive pulmonary disease prevention and management. Arch Intern Med. 2007;167:551-561.

28. Bourbeau J, van der PJ. Promoting effective self-management programmes to improve COPD. Eur Respir J. 2009;33:461-463.

29. Jones RC, Donaldson GC, Chavannes NH, et al. Derivation and validation of a composite index of severity in chronic obstructive pulmonary disease: The DOSE Index. Am J Respir Crit Care Med. 2009;180:1189-1195.

30. Belza B, Steele BG, Cain K, et al. Seattle Obstructive Lung Disease Questionnaire: Sensitivity to outcomes in pulmonary rehabilitation in severe pulmonary illness. J Cardiopulm Rehabil. 2005;25: 107-114.

31. Ferrer M, Alonso J, Morera J, et al. Chronic obstructive pulmonary disease stage and health-related quality of life. The Quality of Life of Chronic Obstructive Pulmonary Disease Study Group. Ann Intern Med. 1997;127:1072-1079.

32. Carrasco GP, de Miguel DJ, Rejas GJ, et al. Negative impact of chronic obstructive pulmonary disease on the health-related quality of life of patients. Results of the EPIDEPOC study. Health Qual Life Outcomes. 2006;4:31.

33. Fletcher M, van der Molen T, Salapatas M, Walsh J. COPD uncovered: A report. ISBN 978-0-9565537. 2009.

34. Adams R, Chavannes N, Jones K, Ostergaard MS, Price D. Exacerbations of chronic obstructive pulmonary disease - a patients' perspective. Prim Care Respir J. 2006;15:102-109.

35. Wyrwich KW, Metz SM, Kroenke K, et al. Measuring patient and clinician perspectives to evaluate change in health-related quality of life among patients with chronic obstructive pulmonary disease. J Gen Intern Med. 2007;22:161-170.

36. Confronting COPD in America: Executive Summary. http://www aarc org/resources/confronting_copd/exesum.pdf. Accessed February 3, 2011.

37. Ries AL. Impact of chronic obstructive pulmonary disease on quality of life: The role of dyspnea. Am J Med. 2006;119:12-20.

38. Oga T, Nishimura K, Tsukino M, et al. Longitudinal deteriorations in patient reported outcomes in patients with COPD. Respir Med. 2007;101:146-153. 
39. Cruse MA. The impact of change in exercise tolerance on activities of daily living and quality of life in COPD: A patient's perspective. COPD. 2007;4:279-281.

40. Kessler R, Stahl E, Vogelmeier C, et al. Patient understanding, detection, and experience of COPD exacerbations: An observational, interviewbased study. Chest. 2006;130:133-142.

41. Miravitlles M, Molina J, Naberan K, et al. Factors determining the quality of life of patients with COPD in primary care. Ther Adv Respir Dis. 2007;1:85-92.

42. Cote CG, Pinto-Plata V, Kasprzyk K, Dordelly LJ, Celli BR. The 6-min walk distance, peak oxygen uptake, and mortality in COPD. Chest. 2007; 132:1778-1785.

43. Esteban C, Quintana JM, Moraza J, et al. Impact of hospitalisations for exacerbations of COPD on health-related quality of life. Respir Med. 2009;103:1201-1208.

44. Mannino DM, Gagnon RC, Petty TL, Lydick E. Obstructive lung disease and low lung function in adults in the United States: Data from the National Health and Nutrition Examination Survey, 1988-1994. Arch Intern Med. 2000;160:1683-1689.

45. Jones PW. Health status: What does it mean for payers and patients? Proc Am Thorac Soc. 2006;3:222-226.

46. Jones PW, Harding G, Berry P, et al. Development and first validation of the COPD Assessment Test. Eur Respir J. 2009;34:648-654.

47. Van der MT, Willemse BW, Schokker S, et al. Development, validity and responsiveness of the Clinical COPD Questionnaire. Health Qual Life Outcomes. 2003;1:13.
48. Fletcher CM, Elmes PC, Fairbairn MB, et al. The significance of respiratory symptoms and the diagnosis of chronic bronchitis in a working population. $\mathrm{Br}$ Med J. 1959;2:257-266.

49. Bestall JC, Paul EA, Garrod R, et al. Usefulness of the Medical Research Council (MRC) dyspnoea scale as a measure of disability in patients with chronic obstructive pulmonary disease. Thorax. 1999;54:581-586.

50. Damato S, Bonatti C, Frigo V, et al. Validation of the Clinical COPD questionnaire in Italian language. Health Qual Life Outcomes. 2005;3:9.

51. Stallberg B, Nokela M, Ehrs PO, Hjemdal P, Jonsson EW. Validation of the clinical COPD Questionnaire (CCQ) in primary care. Health Qual Life Outcomes. 2009;7:26.

52. Kocks JW, Tuinenga MG, Uil SM, et al. Health status measurement in COPD: The minimal clinically important difference of the clinical COPD questionnaire. Respir Res. 2006;7:62.

53. Healthcare professional user guide. COPD Assessment Test: Expert guidance on frequently asked questions. September, 2009. Available at: http://catestonline.co.uk/images/CAT_Expert\%20Guidance_ Issue1_2009.pdf. Accessed on April 1, 2011.

54. Horne R, Price D, Cleland J, et al. Can asthma control be improved by understanding the patient's perspective? BMC Pulm Med. 2007;7:8.
International Journal of COPD

\section{Publish your work in this journal}

The International Journal of COPD is an international, peer-reviewed journal of therapeutics and pharmacology focusing on concise rapid reporting of clinical studies and reviews in COPD. Special focus is given to the pathophysiological processes underlying the disease, intervention programs, patient focused education, and self management protocols.

\section{Dovepress}

This journal is indexed on PubMed Central, MedLine and CAS. The manuscript management system is completely online and includes a very quick and fair peer-review system, which is all easy to use. Visit http://www.dovepress.com/testimonials.php to read real quotes from published authors. 